\title{
Electromagnetic Wave Absorption Properties of Novel Green Composites Coconut Fiber Coir and Charcoal Powder over X-band Frequency for Electromagnetic Wave Absorbing Applications
}

\author{
N. F. N. Yah ${ }^{1}$, H. A. Rahim ${ }^{1 *}$, Y. S. Lee ${ }^{2}$, F. H. Wee ${ }^{1}$, and H. H. Zainal ${ }^{1}$ \\ ${ }^{1}$ Bioelectromagnetic Research Group (BioEM), School of Computer and Communication Engineering, Universiti Malaysia \\ Perlis (UniMAP), Kampus Pauh Putra, 02600, Arau, Perlis, Malaysia \\ ${ }^{2}$ Department of Electronic Engineering Technology, Fakulti Teknologi Kejurutereaan, Universiti Malaysia Pelis (UniMAP), \\ Perlis, Malaysia \\ *corresponding author, E-mail: haslizarahim@unimap. edu.my
}

\begin{abstract}
This paper presents the electromagnetic wave (EW) absorption properties in terms of complex permittivity and permeability of novel green composites coconut fiber coir and charcoal powder materials. The samples were fabricated using the raw agricultural waste coconut fiber coir, charcoal powder, epoxy resin and hardener with varied composition. The dielectric properties of the materials were characterized using two-port waveguide measurement method over the X-band frequency $(8.2-12.4 \mathrm{GHz})$. The average permittivity value measured is approximately 3.00 with $10 \mathrm{wt} \%$ charcoal has the highest permittivity of 3.59 . Apart from that, all samples exhibit good reflection loss of better than $-25 \mathrm{~dB}$ which means more than $99 \%$ absorption rate. The result shows the composite material is a promising organic material for electromagnetic absorber applications.
\end{abstract}

\section{Introduction}

As an electromagnetic wave travelling in free space penetrates into a material, the wave will be reflected, transmitted or absorbed [1]. The design of electromagnetic wave absorber is enhanced with material having electric or magnetic dipoles. Absorption properties of a material is usually analyzed and determined by two material parameters; permittivity and permeability [1-2]. Permittivity and permeability relate to a material's ability to transmit an electric field and magnetic field respectively. Based on these parameters, materials are classified as either dielectric or magnetic. Complex permittivity $\left(\varepsilon^{*}=\varepsilon^{\prime}-j \varepsilon^{\prime \prime}\right)$ and complex permeability $\left(\mu^{*}=\mu^{\prime}-j \mu^{\prime \prime}\right)$ describe the interactions of electromagnetic wave through a material. The real parts of complex permittivity and permeability $\left(\varepsilon^{\prime}, \mu^{\prime}\right)$ are associated with electric and magnetic energy storage, whereas the imaginary parts $\left(\varepsilon^{\prime \prime}, \mu^{\prime \prime}\right)$ represent the dielectric and magnetic loss or energy dissipated within a material. Furthermore, the ratio of imaginary parts (energy loss) to the real parts (energy stored) is the loss tangent of the complex permittivity and permeability. Thus, for an electromagnetic wave absorber, high imaginary parts of complex permittivity and permeability will enable greater absorption.

Recently many researchers show great interest in EM wave absorbing material due to widespread use in military and civil applications, such as anechoic chambers, EM shielding, and radiation proof material [3]. Various kinds of research and work have been done into finding the ideal EM wave absorber with a lightweight, thin layer, good absorption and wider broadband. EM wave absorbers are mostly made of polymer and absorbing material composite such as carbon nanotubes, ferrite and ultrafine metal powder [1]. However, there has been growing expectation by consumers and industry to use sustainable materials or green technologies [4]. Due to this, organic materials such as agricultural wastes have gained a lot of interest among researchers. Different types of microwave absorbers from varied agricultural wastes have been studied such as rice husk [5] , sugar cane baggase [6], corn stove [7], dried banana leave [8], oil palm ash [9] and many others. Most of the absorbers offer good absorption performances that surpass the threshold of $-10 \mathrm{~dB}$ reflection loss. For example better than $-20 \mathrm{~dB}$ for rise husk and $-30 \mathrm{~dB}$ sugar cane baggase, as well as average of $-45.2 \mathrm{~dB}$ for dried banana leaves.

To the best of authors' knowledge, no work has been done for the electromagnetic wave absorption properties of composite coconut fiber coir over the X-band frequency. Coconut fiber coir is a coconut by-product mostly from coconut milk processing field that is physically abundant and cheap [10]. Typically the coconut wastes such as husk/peat are used in agricultural and horticultural as a natural organic fertilizer while the coconut shells are burned into charcoal. Therefore, in this work, the performance of green organic coconut fiber coir as a microwave absorber was investigated. This paper is organized into four parts. In part two the preparation and measurement of the sample are explained. Next the paper discusses and analyzes the result obtained from the measurement. Lastly the potential of coconut fiber coir as microwave absorber briefly discuss in conclusion. 


\section{Method and material}

The first step of the measurement is to collect the material which is coconut fiber coir for the sample preparation. The material was grinded into powder form using grinding machine. Then, it was mixed with different percentage of charcoal and also the epoxy resin as bonding agent and later mixed with epoxy hardener as hardening agent. The composition of the coconut fiber coir with charcoal, resin and hardener are $50 \mathrm{wt} \%, 40 \mathrm{wt} \%$ and $10 \mathrm{wt} \%$ respectively as represent in Table 1.

Table 1 : Compositions of each sample

\begin{tabular}{ccccc}
\hline Sample & $\begin{array}{c}\text { Coconut } \\
\text { Fiber Coir }\end{array}$ & Charcoal & $\begin{array}{c}\text { Epoxy } \\
\text { Resin }\end{array}$ & $\begin{array}{c}\text { Epoxy } \\
\text { Hardener }\end{array}$ \\
\hline $\begin{array}{c}0 \mathrm{wt} \% \\
\text { charcoal }\end{array}$ & $5.0 \mathrm{~g}$ & $0.0 \mathrm{~g}$ & $4.0 \mathrm{~g}$ & $1.0 \mathrm{~g}$ \\
$\begin{array}{c}5 \mathrm{wt} \% \\
\text { charcoal }\end{array}$ & $4.5 \mathrm{~g}$ & $0.5 \mathrm{~g}$ & $4.0 \mathrm{~g}$ & $1.0 \mathrm{~g}$ \\
$\begin{array}{c}10 \mathrm{wt} \% \\
\text { charcoal }\end{array}$ & $4.0 \mathrm{~g}$ & $1.0 \mathrm{~g}$ & $4.0 \mathrm{~g}$ & $1.0 \mathrm{~g}$ \\
$\begin{array}{c}15 \mathrm{wt} \% \\
\text { charcoal }\end{array}$ & $3.5 \mathrm{~g}$ & $1.5 \mathrm{~g}$ & $4.0 \mathrm{~g}$ & $1.0 \mathrm{~g}$ \\
$\begin{array}{c}100 \mathrm{wt} \% \\
\text { charcoal }\end{array}$ & $0.0 \mathrm{~g}$ & $5.0 \mathrm{~g}$ & $4.0 \mathrm{~g}$ & $1.0 \mathrm{~g}$ \\
\hline
\end{tabular}

The samples were fabricated in a rectangular mould with the same dimension as the WR-90 waveguide adapter as shown in Fig.1. The waveguide operates in the specific frequency range of $x$-band $(8.2 \mathrm{GHz}-12.4 \mathrm{GHz})$. Five samples of coconut fiber coir / charcoal composite with different weight percentage $(0 \mathrm{wt} \%, 5 \mathrm{wt} \%, 10 \mathrm{wt} \%, 15 \mathrm{wt} \%$, and $100 \mathrm{wt} \%$ ) of charcoal powder were fabricated. Fig.2 displays the five samples fabricated for this experiment.

The characterization of coconut fiber coir was conducted through extensive measurements using high performance measurement equipment which is two-port Agilent Network Analyzer model PNA and software Agilent Technologies 85071E. The complex permittivity and permeability of the samples were measured over the Xband frequency using two-port waveguide measurement method with Agilent Network Analyzer [11]. Two-port waveguide transmission line method was applied for high accuracy values.

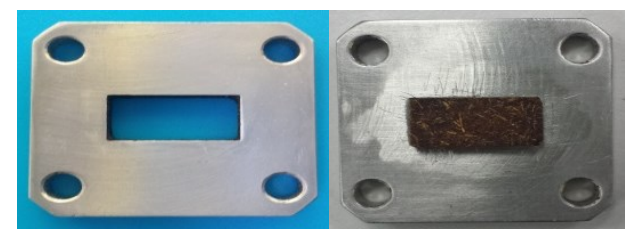

Figure 1: The sample holder used as rectangular mould with dimension of length $22.860 \mathrm{~mm}$ and width $10.160 \mathrm{~mm}$

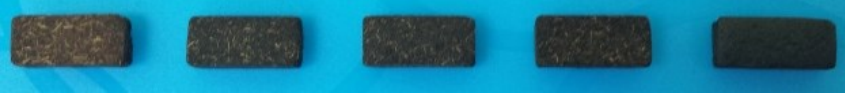

Figure 2: Fabricated samples of coir, $5 \mathrm{wt} \%$ charcoal, $10 \mathrm{wt} \%$ charcoal, $15 \mathrm{wt} \%$ charcoal and charcoal respectively from left to right

\section{Result and discussion}

Fig.3 to 6 show the relative complex permittivity $\left(\varepsilon_{r}=\right.$ $\left.\varepsilon_{r}{ }^{\prime}-j \varepsilon_{r}{ }^{\prime \prime}\right)$ and relative complex permeability $\left(\mu_{r}=\mu_{r}{ }^{\prime}-\right.$ $\left.j \mu_{r}{ }^{\prime \prime}\right)$ in the frequency range of $8.2-12.4 \mathrm{GHz}$ obtained from the measurement. The real parts of permittivity and permeability denote the electric and magnetic storage ability respectively, while the imaginary parts represent the energy dissipation. The tangent loss is the ratio of imaginary to real value $\left(\tan \delta=\varepsilon_{r} " / \varepsilon_{r}^{\prime}\right)$.

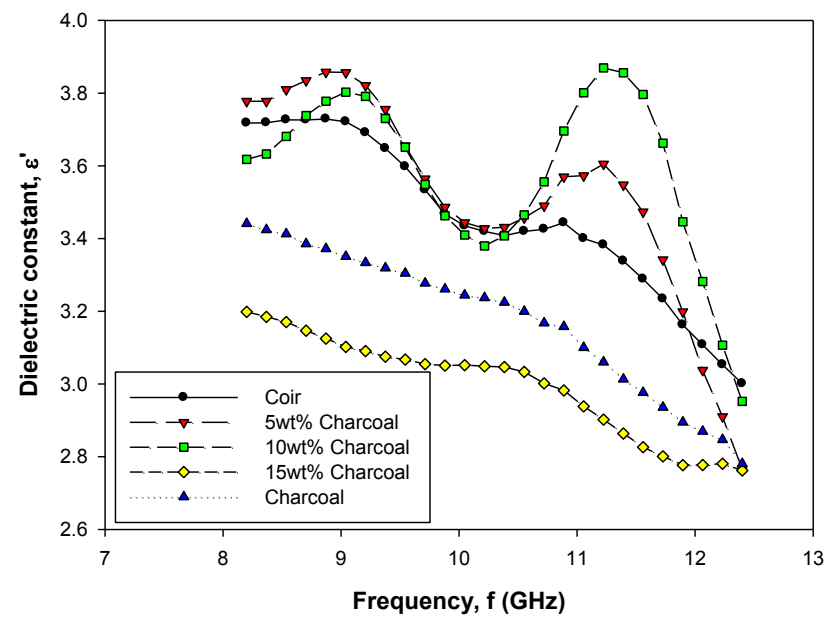

Figure 3 : Dielectric constant of 5 different samples



Figure 4: Dielectric tangent loss of 5 different samples 


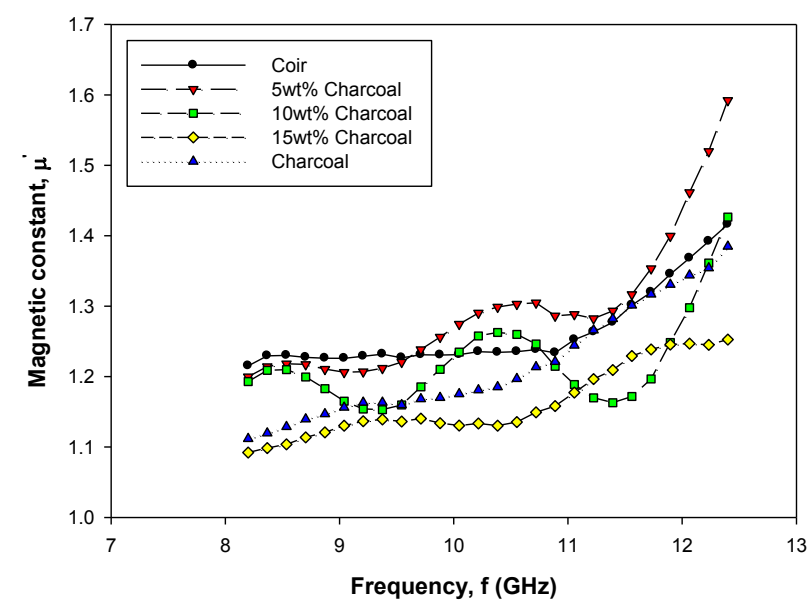

Figure 5 : Magnetic constant of 5 different samples

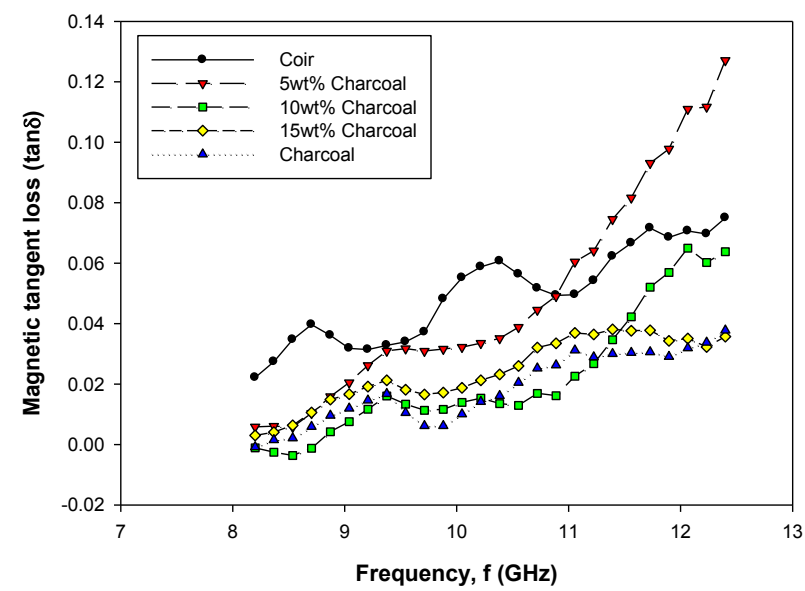

Figure 6: Magnetic tangent loss of 5 samples

From Fig. 3, it can be observed that the performance of the samples varies when the frequency increases from $8.2 \mathrm{GHz}$ to $12.4 \mathrm{GHz}$. However, the result shows that the samples with $5 \mathrm{wt} \%$ and $10 \mathrm{wt} \%$ of charcoal exhibit higher value of dielectric constant compared to the other composition. The permittivity values exhibit a moderate decreasing trend over the frequency. The decreasing trend of permittivity with increasing frequency can be attributed to the variation of polarization with frequency [12]. On the other hand, Fig. 4 shows that sample with only coconut fiber coir has highest value of dielectric tangent loss and its value is decreasing as the content of charcoal in the sample increasing. The tangent loss of coir sample is significantly higher than other samples especially charcoal with approximately 2 times higher than charcoal. In addition, the graph in Fig. 6 also shows that the magnetic tangent loss of the samples increases with the increases of frequency. Higher loss factor enables greater electromagnetic wave absorption [1]. Thus, with an optimal percentage of charcoal powder, the best performance for coconut fiber coir composite microwave absorber could be achieved.
In order to analyze the absorption properties of coconut fiber coir and charcoal composites, the electric conductivity $(\sigma)$ of the samples were calculated using equation (1) where $\omega$ is the angular frequency $(\omega=2 \pi f), \varepsilon_{\mathrm{o}}$ is the permittivity of free space and $\varepsilon_{r}$ " is the imaginary part of relative complex permittivity.

$\sigma=\omega \varepsilon_{o} \varepsilon_{r}$

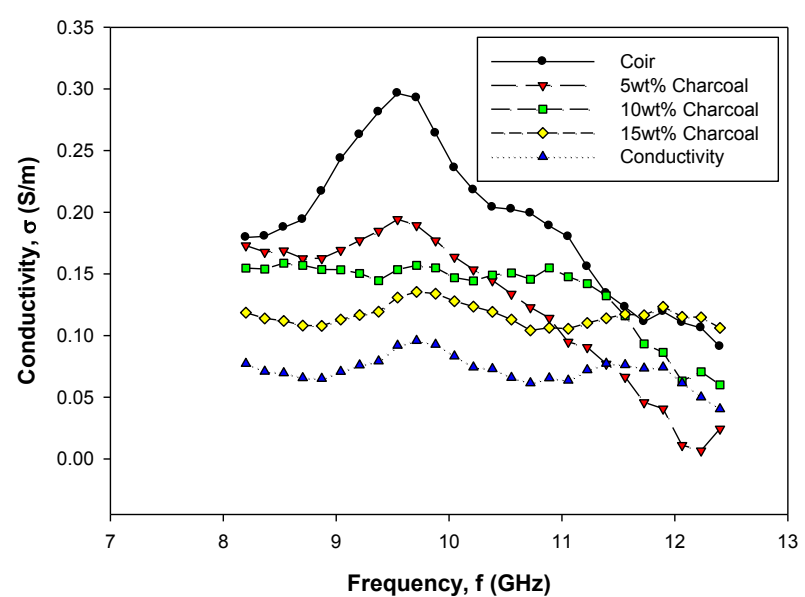

Figure 7: Conductivity of the five samples over $\mathrm{x}$-band frequency range.

A comparison on conductivity of the five samples is presented in Fig.7. The coconut fiber coir sample shows the highest value of conductivity among the five samples with the charcoal sample is the lowest. The average conductivity of coconut fiber coir sample is approximately 2.5 times higher than the charcoal sample. In general, from the calculation, higher charcoal content lower the conductivity of the sample as shown in Fig. 7. The conductivity value is decreasing as the percentage of charcoal in a sample is increasing which is similar with the dielectric tangent loss. On the other hand, the penetration depth $\left(d_{p}\right)$ of each sample is calculated from Equation (2):

$d_{p}=\frac{c}{2 \pi f \sqrt{2 \varepsilon^{\prime}\left[\sqrt{1+\left(\frac{\varepsilon^{\prime \prime}}{\varepsilon^{\prime}}\right)^{2}}-1\right]}}$,

where $\mathrm{c}$ is the speed of light $\left(c=3.0 \times 10^{8} \mathrm{~m} / \mathrm{s}\right)$ and $\mathrm{f}$ is the frequency $(\mathrm{Hz})$. Penetration depth is to measure how depth of electromagnetic wave propagates and penetrate into material. So from equation (2) we could determine how far the electromagnetic wave travels into the material. Fig.8 shows the calculated penetration depth of each sample over the $\mathrm{x}$-band frequency range. There is not much different in value of penetration depth between the samples. However, it is noted that samples with higher charcoal content exhibit more penetration depth which means that it allows electromagnetic wave to travel further. There is spike in sample $5 \mathrm{wt} \%$ charcoal that might be due to the presence of noise during measurement. 


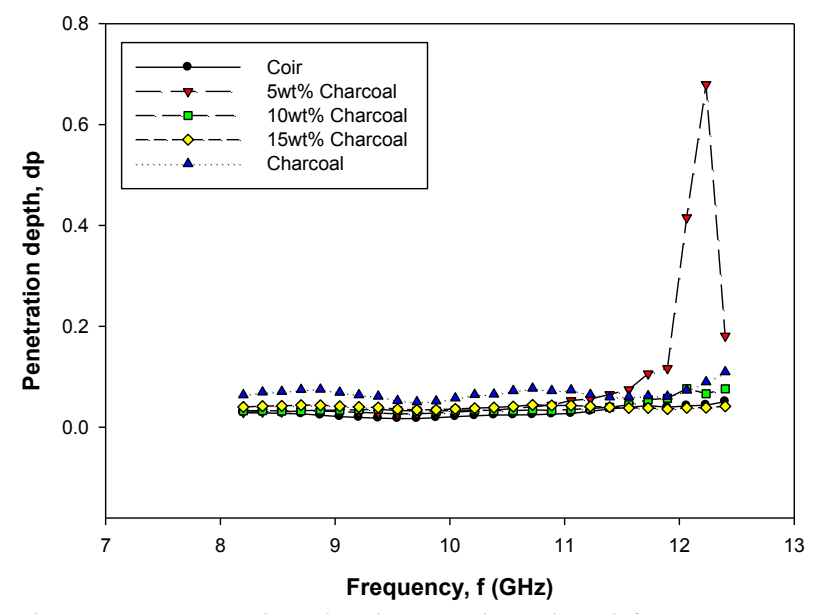

Figure 8: Penetration depth over the $\mathrm{x}$-band frequency range

Using equation (3) to (6), the attenuation constant $(\alpha)$ and phase constant $(\beta)$ of the samples are calculated.

$\varepsilon=\varepsilon_{o} \varepsilon_{r}$,

$\mu=\mu_{o} \mu_{r}$

$\alpha=\omega \sqrt{\frac{\mu \varepsilon}{2}}\left[\sqrt{\left(1+\frac{\sigma^{2}}{\omega^{2} \varepsilon^{2}}\right)}-1\right]^{\frac{1}{2}}$,

$\beta=\omega \sqrt{\frac{\mu \varepsilon}{2}}\left[\sqrt{\left(1+\frac{\sigma^{2}}{\omega^{2} \varepsilon^{2}}\right)}+1\right]^{\frac{1}{2}}$,

where $\varepsilon_{\mathrm{o}}$ and $\mu_{\mathrm{o}}$ are the permittivity and permeability of free space respectively $\left(\varepsilon_{o}=8.854 \times 10^{-12} \mathrm{~F} / \mathrm{m}, \mu_{o}=\right.$ $1.256 \times 10^{-6} \mathrm{H} / \mathrm{m}$ )

Fig. 9 summarized the attenuation constant and phase constant of all five samples over the $\mathrm{x}$-band frequency. From Fig. 9(a), the attenuation constant of coconut fiber coir sample is the highest compared to the other. Noticeably, the value of attenuation constant is decreasing with increasing of charcoal content in the sample which consistent with the tangent loss in Fig. 5. In addition, all samples exhibit peak attenuation constant in the frequency range of $9.5-10 \mathrm{GHz}$. Similarly with phase constant in Fig. 9(b), too much charcoal content in the sample lower the phase constant. The phase constant is increasing with frequency.

To further study and compare the electromagnetic wave absorption properties of coconut fiber coir and charcoal composites, the reflection losses (RL) can be calculated based on the transmission line theory as in Equation (7) and (8):

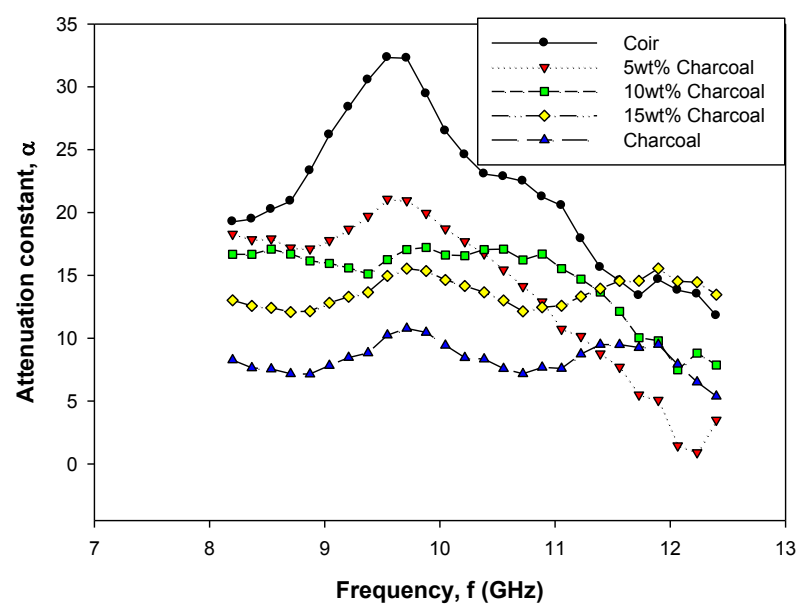

(a)

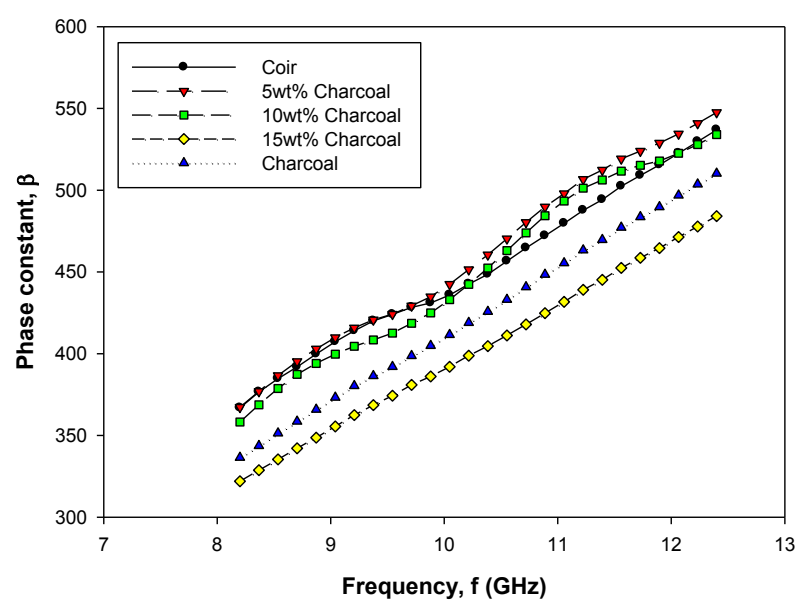

(b)

Figure 9: Comparison of the five samples over the x-band frequency for (a) attenuation constant (b) phase constant

$Z=\sqrt{\frac{\mu_{r}}{\varepsilon_{r}}} \tanh \left[j\left(\frac{2 \pi f d}{c}\right) \sqrt{\mu_{r} \varepsilon_{r}}\right]$,

$R L=20 \log \left|\frac{Z-1}{Z+1}\right|$,

where $Z$ is the impedance matching characteristic $\left(Z=Z_{\text {in }} / Z_{o}\right.$ ) and $d$ is the thickness of the fabricated sample. 


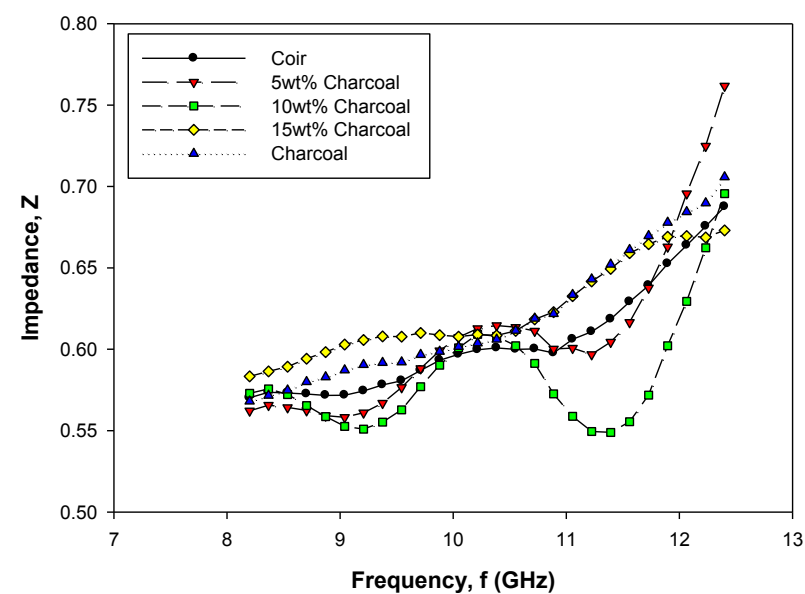

(a)

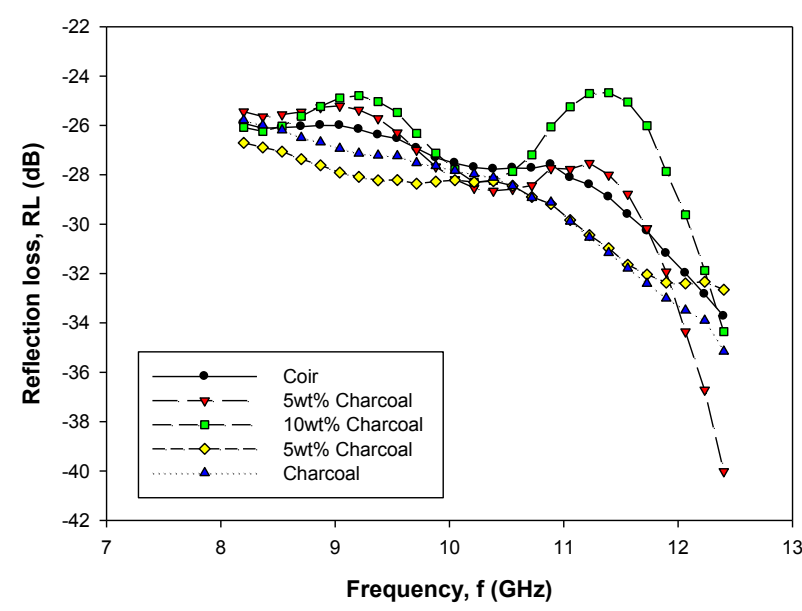

(b)
The calculated impedance matching characteristics and reflection losses of the samples are present in Fig.10. From the graph in Fig. 10(a), the value of impedance matching characteristic, $\mathrm{Z}$ is increasing with increasing frequency. Moreover, the absorption performance or reflection loss is improved as the value of $\mathrm{Z}$ is close to 1 as shown in Fig. 10(a) and (b). The peak values of reflection loss of all samples are shifted to the higher frequency with an average of approximately $40 \%$ increase in reflection loss. Overall, the samples demonstrated a good absorption performance with average of reflection loss better than $-25 \mathrm{~dB}$ which means more than $99 \%$ absorption rate.

Table 2 presents the summary of the average absorption properties over the $\mathrm{x}$-band frequency for the different coconut fiber coir and charcoal composite samples obtained in this work. For better comparison, the average dielectric constant and reflection loss of some electromagnetic wave absorbing material studied previously are listed in Table 3 . The result implies that the coconut fiber coir is comparable and can be potentially used in electromagnetic absorbing applications.

Table 3: Average dielectric constant and reflection loss of some material

\begin{tabular}{lccc}
\hline Material & $\begin{array}{c}\text { Dielectric } \\
\text { constant }\end{array}$ & $\begin{array}{c}\text { Reflection } \\
\text { loss }\end{array}$ & Ref. \\
\hline $\begin{array}{l}\text { Coco-peat } \\
\begin{array}{l}\text { Rice husk and } \\
\text { carbon }\end{array}\end{array}$ & $>3.0$ & $<-30 \mathrm{~dB}$ & {$[10]$} \\
$\begin{array}{l}\text { nanotubes } \\
\text { Coconut fiber } \\
\text { coir and } \\
\text { charcoal }\end{array}$ & $>3.0$ & $<-20 \mathrm{~dB}$ & {$[5]$} \\
\hline
\end{tabular}

Figure 10: Comparison of (a) The impedance matching characteristic, (b) Reflection loss of five samples over the $\mathrm{x}$ band frequency

Table 2: The average of absorption properties over the $\mathrm{x}$-band frequency

\begin{tabular}{cccccccc}
\hline Sample & $\boldsymbol{\varepsilon}^{\prime}$ & $\boldsymbol{\mu}^{\prime}$ & $\boldsymbol{\sigma}$ & $\mathbf{d}_{\mathbf{p}}$ & $\boldsymbol{\alpha}$ & $\boldsymbol{\beta}$ & $\mathbf{R L}$ \\
\hline $\mathbf{C o i r}$ & 3.4566 & 1.2617 & 0.1931 & 0.0282 & 21.6581 & 451.5935 & -28.0460 \\
$\begin{array}{c}\mathbf{5 w t \%} \\
\mathbf{C h a r c o a l} \\
\mathbf{1 0 w t \%}\end{array}$ & 3.5246 & 1.2919 & 0.1245 & 0.0891 & 13.7791 & 460.4311 & -28.3375 \\
$\mathbf{C h a r c 0 a l}$ & 3.5905 & 1.2173 & 0.1354 & 0.0398 & 14.7316 & 451.4801 & -26.7260 \\
$\begin{array}{c}\mathbf{1 5 w t} \% \\
\text { Charcoal }\end{array}$ & 2.9948 & 1.1620 & 0.1164 & 0.0397 & 13.6474 & 402.9805 & -29.2444 \\
\begin{tabular}{c} 
Charcoal \\
\hline
\end{tabular} & 3.1781 & 1.2152 & 0.0719 & 0.0674 & 8.3511 & 423.7698 & -29.0561 \\
\hline
\end{tabular}




\section{Conclusions}

As conclusion, the coconut fiber coir and charcoal composite samples with different weight percentage of charcoal were fabricated. The electromagnetic wave absorption properties including complex permittivity and permeability, conductivity, penetration depth, attenuation constant, phase constant, impedance matching characteristics and the reflection loss of the samples were studied and analyzed. The performance of the samples varies when the frequency increases. The result from the measurement shows that coconut fiber coir has promising properties to be developed into a suitable material for microwave absorber.

\section{Acknowledgements}

The authors would like to thank School of Computer and Communication, Universiti Malaysia Perlis for the support and facilities.

\section{References}

[1] F. M. Idris, M. Hashim, Z. Abbas, I. Ismail, R. Nazlan, and I. R. Ibrahim, "Recent developments of smart electromagnetic absorbers based polymercomposites at gigahertz frequencies," J. Magn. Magn. Mater., vol. 405, pp. 197-208, 2016.

[2] S. T. Liu, K. K. Yan, Y. H. Zhang, S. Di Jin, Y. Ye, and $\mathrm{X}$. G. Chen, "Magnesiothermic reduction of rice husk ash for electromagnetic wave adsorption," $J$. Magn. Magn. Mater., vol. 394, pp. 266-273, 2015.

[3] Y. Ding, Q. Liao, S. Liu, H. Guo, Y. Sun, and G. Zhang, "Reduced Graphene Oxide Functionalized with Cobalt Ferrite Nanocomposites for Enhanced Efficient and Lightweight Electromagnetic Wave Absorption," Nat. Publ. Gr., no. April, pp. 1-9, 2016.

[4] X. Du, Z. Zhang, W. Liu, and Y. Deng, "Nanocellulose-based conductive materials and their emerging applications in energy devices - A review," Nano Energy, vol. 35, no. April, pp. 299320, 2017.

[5] L. Y. Seng, F. H. Wee, H. A. Rahim, M. AbdulMalek, Y. K. You, Z. Liyana, and A. A. M. Ezanuddin, "Design of multiple-layer microwave absorbing structure based on rice husk and carbon nanotubes," Appl. Phys. A, vol. 123, no. 1, p. 73, 2017.

[6] Z. Liyana, F. Malek, H. Nornikman, N. A. Mohd Affendi, L. Mohamed, N. Saudin, and A. A. Ali, "Investigation of sugar cane bagasse as alternative material for pyramidal microwave absorber design," IEEE Symp. Wirel. Technol. Appl. ISWTA, pp. 6670, 2012.

[7] B. Smythe, S. Casserly, and D. Arakaki, "Organicbased microwave frequency absorbers using corn stover," IEEE Antennas Propag. Soc. AP-S Int. Symp., pp. 920-921, 2014.
[8] R. Kaur, G. D. Aul, and V. Chawla, "Improved Reflection Loss Performance of Dried Banana Leaves Pyramidal Microwave Absorbers by Coal for Application in Anechoic Chambers," vol. 43, no. July, pp. 157-164, 2015.

[9] I. R. M. Noordin, H. Abdullah Idris, M. N. Taib, J. Md Sharif, A. D. Rosli, A. Zanal, and A. T. Abdullah, "Investigation of oil palm ash microwave absorber for broadband application," Proc. - 2012 IEEE 8th Int. Colloq. Signal Process. Its Appl. CSPA 2012, pp. 232-235, 2012.

[10] B. S. Yew and F. H. Wee, "A GRICULTURAL W ASTE BASED -COCO PEAT M ICROWAVE," Int. J. Eng. Sci. Emerg. Technol., vol. 7, no. 2, pp. 547-554, 2014.

[11] "Agilent Basics of Measuring the Dielectric Properties of Materials," 5989-2589EN, 2013.

[12] S. Kashi, R. K. Gupta, T. Baum, N. Kao, and S. N. Bhattacharya, "Dielectric properties and electromagnetic interference shielding effectiveness of graphene-based biodegradable nanocomposites," Mater. Des., vol. 109, pp. 68-78, 2016. 